\title{
Rheumatoid factor, chronic arthritis and mortality
}

\author{
M Heliövaara, K Aho, P Knekt, A Aromaa, J Maatela, A Reunanen
}

\begin{abstract}
Objective-To investigate chronic arthritis and rheumatoid factor (RF) for their prediction of premature total and cardiovascular mortality.

Methods-In 1978-80, a representative population sample of 8000 Finns aged 30 or more was invited to participate in a comprehensive health examination; $90 \%$ complied. Arthritis was diagnosed on the basis of medical history, symptoms, and physical examination. Serum RF was determined by the sensitised sheep cell agglutination test.

Results-By the end of 19921597 of the subjects had died from all causes, including 876 deaths from cardiovascular diseases. When adjusted for age, gender and smoking, the relative risk of persons with RF positive arthritis dying from any cause was 1.61 (95\% confidence interval (CI) 1.03 to $2 \cdot 51$ ); RF negative non-erosive arthritis was not associated with mortality (relative risk $1.03 ; 95 \%$ CI 0.72 to 1.49 ). In the absence of arthritis, 'false positive' RF titres $\geqslant 128$ predicted cardiovascular deaths with a relative risk of $1.74(95 \% \mathrm{CI}$ $1 \cdot 06$ to $2 \cdot 86$ ).

Conclusion-Both RF positive arthritis and false positive $R F$ reactions predict mortality, but through different disease patterns.
\end{abstract}

(Ann Rheum Dis 1995; 54: 811-814)

It has long been known that patients with rheumatoid arthritis have reduced life expectancy. ${ }^{1-4}$ In general, the excess mortality associated with arthritis has been more clear in series of clinically recruited patients than in population based studies. ${ }^{5-7}$ Many patients die prematurely as a result of either the disease or its treatment, but the reduced life span does not necessarily imply that chronic arthritis per se affects longevity. In particular, an excess of deaths has been observed from infections and from renal diseases. Likewise, several studies have suggested excess mortality from gastrointestinal causes, notably complications of peptic ulcer, and from cardiovascular causes. Smoking is a risk factor for rheumatoid arthritis, in particular for rheumatoid factor (RF) positive arthritis in men, ${ }^{8}$ but previous studies $^{1-7}$ have not considered the possibility that at least part of the excess mortality associated with arthritis may be attributable to smoking.

Circumstantial evidence from series of patients and some evidence from longitudinal population studies suggest that autoantibodies separate from their 'mother' diseases could act as risk determinants for premature death. ${ }^{9}$ Autoantibodies appeared to be associated with excess mortality from cardiovascular causes and cancer in a rural population in western Australia; ${ }^{10}$ however, the figures were not corrected for age and may therefore have been biased. In a case-control study nested within a population cohort from eastern Finland, RF and antinuclear antibodies, as determined from baseline specimens, were shown to predict mortality from cardiovascular causes. ${ }^{11}$

The Mini-Finland Health Survey is an epidemiological project with the aim of comprehensive evaluation of the health of the Finnish adult population. The prevalence, mutual relationships, and determinants of arthritides and RF in this survey have been described previously. ${ }^{12-14}$ We have investigated chronic arthritis and RF for their prediction of total and cardiovascular mortality.

\section{Subjects and methods}

POPULATION

The study population was a stratified two stage cluster sample drawn from the population register to represent Finnish adults aged 30 years or more..$^{15}$ In the first stage, 40 representative areas were selected. In the second stage, a systematic sample of inhabitants was drawn from each area. The sample consisted of 8000 persons ( 3637 men and 4363 women) from 69 municipalities.

\section{BASELINE EXAMINATION}

The data were collected during 1977-80. The examinations were carried out by the Mobile Clinic of the Social Insurance Institution in two phases: a screening phase and a diagnostic (clinical) phase. A total of 7217 persons (90\% of the sample) participated in the screening phase. The distribution of gender, age, and level of education among the participants corresponded closely to that of the whole Finnish population. ${ }^{15}$

The methods used for studying musculoskeletal diseases and the basic results of the Mini-Finland Health Survey have been described elsewhere. ${ }^{1516}$ Together with the invitation to attend the health examination, the subjects received a questionnaire requesting information on previous diseases, hospital stays, operations, and medications. As part of the screening examination, blood was taken for serological studies and the Waaler-Rose (sensitised sheep cell agglutination) test was subsequently performed. A specific interview covering the musculoskeletal system included questions on pain and disorders, and on their 
consequences. To screen for musculoskeletal impairment, a standardised joint function test was performed by specially trained nurses.

The subjects with a disease history, symptoms, or findings suggestive of musculoskeletal diseases were asked to participate in the diagnostic (clinical) phase, on average, three and a half months after the screening examination. There were 3775 persons $(52 \%$ of those examined) fulfilling at least one of the screening criteria; 3434 (91\%) participated. Physical examinations were carried out by specially trained physicians according to a standardised written procedure ${ }^{121516}$ that included measures for grading deformity, mobility, and tenderness of all limb joints. Arthritis was diagnosed on the basis of medical history, symptoms, and physical examination, and further divided into different diagnostic subcategories. The present study concerns those patients who had chronic inflammatory polyarthritis but were not diagnosed as having ankylosing spondylitis or gouty arthritis. As serological test results were not available in this phase, the data on arthritis and RF were independent in this study.

The Waaler-Rose test was performed on microtitre plates with U shaped wells. Natural agglutinins were first absorbed from the serum to be tested. Sheep red blood cells were sensitised with $33 \%$ of the minimum agglutinating dose of amboceptor obtained by prolonged immunisation. The plates were stored overnight at $4^{\circ} \mathrm{C}$ in a refrigerator, after which the readings were made on the basis of sedimentation patterns.

Posteranterior radiographs of the hands and wrists were taken for the subjects participating in the clinical phase. Standard criteria ${ }^{17} 18$ were used for assessing erosive changes. The readings were made by a radiologist who had no information on the clinical or serological findings.

The methods used for diagnosing cardiovascular diseases, the prevalence of these conditions, and other overall results of the MiniFinland Health Survey have been described elsewhere. ${ }^{1516}$ At the screening phase, the subjects were interviewed about their cardiovascular symptoms using specific structured formulas, blood pressure was measured, and an electrocardiogram and chest radiographs were taken. The diagnostic phase of the health examination consisted of a standardised clinical examination carried out by specially trained physicians, who worked according to detailed written instructions, applying uniform diagnostic criteria. ${ }^{15}$

Smoking history was obtained in a standard interview. ${ }^{15}$ The following categories were used: never smoked; ex-smoker; current smoker of pipe, cigar, or fewer than 10 cigarettes a day; current smoker of 10 to 19 cigarettes a day; current smoker of 20 cigarettes or more a day.

FOLLOW UP

The mortality of the examinees has been systematically followed ever since the baseline examination. This information was obtained from the Central Statistical Office of Finland. The principal causes of death were coded according to the 8th Revision of the International Classification of Diseases. This report covers the deaths occurring until the end of 1992, and represents a follow up of 13-15 years and an overall experience of 89149 person-years.

\section{STATISTICAL METHODS}

Cox's life table regression model was used to estimate the associations between arthritis and RF and mortality. ${ }^{19}$ Confounding and effect modifying factors were also entered into the model. Adjusted relative risks and their 95\% confidence intervals were based on this model.

\section{Results}

At the baseline examination, chronic polyarthritis was diagnosed in $175(2 \cdot 4 \%)$ persons; of these, 40 were RF positive by sensitised sheep cell agglutination. Among those with no arthritis, 149 had 'false positive' RF reactions.

In all, 1597 deaths occurred during the 89149 person-years of follow up; of these 876 were from cardiovascular causes. The figure shows survival plots by arthritis and RF status. RF positive arthritis was significantly associated with total mortality, whereas RF negative arthritis as a whole did not predict life expectancy (table 1), though a small subgroup comprising seronegative arthritis with erosive changes in hand radiographs seemed to predict mortality. No significant associations were noted between any type of arthritis and cardiovascular mortality.

False positive RF titres of $\geqslant 128$ significantly predicted both total mortality and, in particular, cardiovascular deaths (table 1). The significant prediction of cardiovascular mortality was found only for those diagnosed as having some established cardiovascular disease at the baseline examination, but a similar, non-significant association appeared to be true also for those without such disease at study entry (table 2). No increase in mortality was observed in persons with RF titres of 32 or 64 .

Smoking was significantly associated with both the prevalence of $\mathrm{RF}$ and subsequent mortality, and could thus act as a potential confounder. Nevertheless, when adjusted for age, gender, and smoking, the associations between RF positive arthritis and total mortality and between false positive RF and cardiovascular mortality remained significant (table 1).

\section{Discussion}

The population sample of the Mini-Finland Health Survey was screened by the sensitised sheep cell agglutination test, which is specific, though not particularly sensitive. Persons with RF positive arthritis according to this test were found to have substantially higher total mortality than the population as a whole. Likewise, persons with erosive arthritis who were 

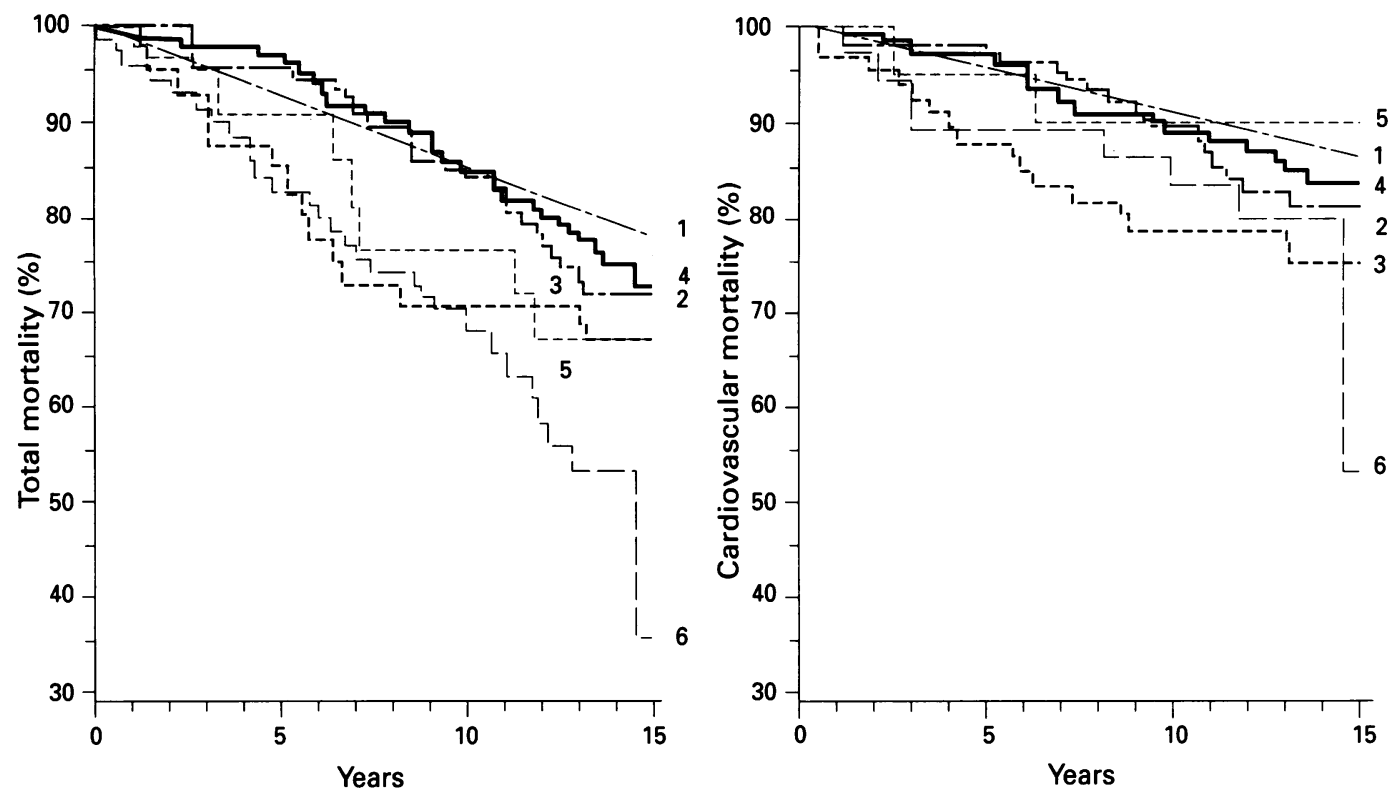

Kaplan-Meier survival functions of subjects with: neither arthritis nor $R F$ determined by sensitised sheep cell agglutination test (1); no arthritis but $R F$ titre of 32 or 64 (2); no arthritis but $R F$ titre of $\geqslant 128$ (3); non-erosive $R F$ negative arthritis (4); erosive $R F$ negative arthritis (5); erosive $R F$ positive arthritis (6).

Table 1 Total and cardiovascular mortality by arthritis and rheumatoid factors (RF) (determined by sensitised sheep cell agglutination test), age, gender and smoking. Adjusted relative risks (RR) and $95 \%$ confidence intervals (CI)

\begin{tabular}{|c|c|c|c|c|c|c|c|}
\hline \multirow[t]{2}{*}{ Explanatory variable } & \multirow{2}{*}{$\begin{array}{l}\text { No of } \\
\text { subjects } \\
\text { examined }\end{array}$} & \multicolumn{3}{|c|}{ Total mortality } & \multicolumn{3}{|c|}{ Cardiovascular mortality } \\
\hline & & $\begin{array}{l}\text { No of } \\
\text { deaths }\end{array}$ & $R R$ & $95 \% C I$ & $\begin{array}{l}\text { No of } \\
\text { deaths }\end{array}$ & $R R$ & $95 \% C I$ \\
\hline Age ( $R R$ per standard deviation: $14 \cdot 2 \mathrm{yr}$ ) & 7217 & 1597 & $4 \cdot 10$ & $\begin{array}{l}\text { Adjustec } \\
3.86 \text { to } 4.36\end{array}$ & $\begin{array}{l}\text { or gender: } \\
876\end{array}$ & $4 \cdot 77$ & $4 \cdot 37$ to $5 \cdot 14$ \\
\hline $\begin{array}{l}\text { Gender } \\
\text { Men } \\
\text { Women }\end{array}$ & $\begin{array}{l}3322 \\
3895\end{array}$ & $\begin{array}{l}856 \\
741\end{array}$ & $\begin{array}{l}1 \cdot 00 \\
0 \cdot 48\end{array}$ & 0.43 to 0.53 & $\begin{array}{l}\text { for age: } \\
473 \\
403\end{array}$ & $\begin{array}{l}1.00 \\
0.45\end{array}$ & 0.39 to 0.52 \\
\hline $\begin{array}{l}\text { Smoking } \\
\text { Never smoked } \\
\text { Ex-smoker } \\
\text { Pipe, cigar or }<10 \text { cigarettes per day } \\
10-19 \text { cigarettes per day } \\
\geqslant 20 \text { cigarettes per day }\end{array}$ & $\begin{array}{r}4009 \\
1505 \\
459 \\
603 \\
641\end{array}$ & $\begin{array}{l}827 \\
356 \\
113 \\
143 \\
158\end{array}$ & $\begin{array}{l}1.00 \\
1.12 \\
1.55 \\
2 \cdot 12 \\
2 \cdot 65\end{array}$ & $\begin{array}{l}\text { Adjusted for } \\
0.97 \text { to } 1 \cdot 30 \\
1 \cdot 26 \text { to } 1 \cdot 90 \\
1 \cdot 75 \text { to } 2 \cdot 58 \\
2 \cdot 18 \text { to } 3 \cdot 22\end{array}$ & $\begin{array}{l}\text { e and gen } \\
454 \\
211 \\
57 \\
71 \\
83\end{array}$ & $\begin{array}{l}1 \cdot 00 \\
1 \cdot 23 \\
1 \cdot 44 \\
2 \cdot 09 \\
2 \cdot 86\end{array}$ & $\begin{array}{l}1.01 \text { to } 1.50 \\
1.08 \text { to } 1.93 \\
1.60 \text { to } 2.75 \\
2.19 \text { to } 3.74\end{array}$ \\
\hline $\begin{array}{l}\text { Arthritis and RF } \\
\text { No arthritis, no RF } \\
\text { No arthritis, RF } 32-64 \\
\text { No arthritis, RF } \geqslant 128 \\
\text { Non-erosive arthritis, no RF } \\
\text { Erosive arthritis, no RF } \\
\text { Erosive arthritis, RF } \geqslant 32\end{array}$ & $\begin{array}{r}6893 \\
80 \\
69 \\
114 \\
21 \\
40\end{array}$ & $\begin{array}{r}1495 \\
23 \\
23 \\
29 \\
7 \\
20\end{array}$ & $\begin{array}{l}1 \cdot 00 \\
0.85 \\
1.50 \\
1 \cdot 02 \\
1 \cdot 75 \\
1 \cdot 82\end{array}$ & $\begin{array}{l}\text { Adjusted for } \\
0.56 \text { to } 1.28 \\
0.99 \text { to } 2.26 \\
0.71 \text { to } 1.48 \\
0.83 \text { to } 3.67 \\
1.17 \text { to } 2.83\end{array}$ & $\begin{array}{l}\text { e and gen } \\
819 \\
14 \\
16 \\
17 \\
2 \\
8\end{array}$ & $\begin{array}{l}r: \\
1.00 \\
0.91 \\
1 \cdot 89 \\
1 \cdot 10 \\
0.92 \\
1.31\end{array}$ & $\begin{array}{l}0.53 \text { to } 1.54 \\
1.15 \text { to } 3.10 \\
0.68 \text { to } 1.77 \\
0.23 \text { to } 3.69 \\
0.65 \text { to } 2.63\end{array}$ \\
\hline $\begin{array}{l}\text { No arthritis, no RF } \\
\text { No arthritis, RF } 32-64 \\
\text { No arthritis, RF } \geqslant 128 \\
\text { Non-erosive arthritis, no RF } \\
\text { Erosive arthritis, no RF } \\
\text { Erosive arthritis, } R F \geqslant 32\end{array}$ & & & $\begin{array}{l}1 \cdot 00 \\
0 \cdot 81 \\
1 \cdot 37 \\
1.03 \\
1 \cdot 88 \\
1.61\end{array}$ & $\begin{array}{l}0.53 \text { to } 1.22 \\
0.91 \text { to } 2.07 \\
0.72 \text { to } 1.49 \\
0.89 \text { to } 3.96 \\
1.03 \text { to } 2.51\end{array}$ & nder an & $\begin{array}{c}\text { oking: } \\
1.00 \\
0.85 \\
1.74 \\
1.11 \\
1.00 \\
1.11\end{array}$ & $\begin{array}{l}0.50 \text { to } 1.44 \\
1.06 \text { to } 2.86 \\
0.69 \text { to } 1.80 \\
0.25 \text { to } 4.00 \\
0.55 \text { to } 2.24\end{array}$ \\
\hline
\end{tabular}

RF negative according to this test seemed to exhibit increased mortality; many of them tested RF positive when more sensitive techniques were used. ${ }^{12}$

About $33 \%$ of patients initially presenting with symptoms and signs of rheumatoid arthritis are RF negative in conventional RF tests. RF negative rheumatoid arthritis tends to run a more favourable course than its $R F$ positive counterpart, and many patients go on to have a complete remission. Thus one would expect the relative proportion of RF negative rheumatoid arthritis cases in cross sectional surveys to be less than $33 \%$. The reverse is

Table 2 Cardiovascular mortality by false positive rheumatoid factors (RF) (determined by sensitised sheep cell agglutination test) in persons with and without cardiovascular diseases at entry. Relative risks (RR) and $95 \%$ confidence intervals (CI) as adjusted for age, gender and smoking

\begin{tabular}{|c|c|c|c|c|c|c|c|c|}
\hline \multirow[t]{2}{*}{ RF titre } & \multicolumn{4}{|c|}{ Cardiovascular disease at entry } & \multicolumn{4}{|c|}{ No cardiovascular disease at entry } \\
\hline & $\begin{array}{l}\text { No of } \\
\text { subjects }\end{array}$ & $\begin{array}{l}\text { No of } \\
\text { deaths }\end{array}$ & $R R$ & $95 \% C I$ & $\begin{array}{l}\text { No of } \\
\text { subjects }\end{array}$ & $\begin{array}{l}\text { No of } \\
\text { deaths }\end{array}$ & $R R$ & $95 \% C I$ \\
\hline $\begin{array}{l}0 \\
32-64 \\
\geqslant 128\end{array}$ & $\begin{array}{r}1942 \\
20 \\
27\end{array}$ & $\begin{array}{r}587 \\
7 \\
12\end{array}$ & $\begin{array}{l}1.00 \\
1.01 \\
1.79\end{array}$ & $\begin{array}{l}0.48 \text { to } 2.14 \\
1.00 \text { to } 3.17\end{array}$ & $\begin{array}{r}4951 \\
60 \\
42\end{array}$ & $\begin{array}{r}232 \\
7 \\
4\end{array}$ & $\begin{array}{l}1.00 \\
1.03 \\
1.43\end{array}$ & $\begin{array}{l}0.48 \text { to } 2.20 \\
0.53 \text { to } 3.85\end{array}$ \\
\hline
\end{tabular}


true, however, as $67 \%$, or even more, of cases in community surveys have shown RF negative findings. ${ }^{20}$ The present study is the first follow up of mortality among such community cases. Life expectancy seemed to be normal in those with non-erosive and RF negative disease. The second and biologically more interesting new finding of the present study was that strongly false positive RF reactions predicted cardiovascular deaths, in particular.

In patients with chronic arthritis, $\mathrm{RF}$ can be associated with increased mortality either by virtue of being a marker of severe disease, or by exerting direct pathogenetic effects. In addition, risk factors for RF positive arthritis, for example smoking, ${ }^{8}$ can have a role. Mortality from infections and from amyloidosis probably reflects the presence of severe disease without the direct influence of RF. However, the proportion of the population of this study who had RF positive arthritis was too small to be analysed for rare causes of death.

One of the antibody mechanisms of tissue damage is the formation of immune complexes; obviously, RF can mediate its effects through this pathway. Typical immune complex vasculitis is characterised by the presence of a necrotising inflammatory response. Such vasculitis, typically associated with high levels of RF, occasionally complicates rheumatoid arthritis. A different kind of vascular lesion, apparently induced immunologically but primarily degenerative in nature with little or no inflammatory component, is frequently observed in murine lupus. ${ }^{21}$ The reasons for this different aetiology are not clear, but may include the rate and duration of immune complex formation or availability of certain mediators of inflammation. It has been suggested that vascular deposition of immune complexes associated with incidental immune reactions, ${ }^{22}{ }^{23}$ or persistent low grade immune reactions, ${ }^{24}$ might provide a significant component in the origin of human atheromatous disease, particularly in those with increased serum lipid concentrations.

The above considerations provided the stimulus for us to seek associations of RF positive arthritis with both total and cardiovascular mortality and, in the case of false positive RF reactions, cardiovascular diseases.

Rheumatoid arthritis is frequently preceded by an immunological process characterised by the occurrence of RF and certain other marker antibodies. ${ }^{25}$ Smoking has been associated with false positive RF reactions in an Australian population survey ${ }^{26}$ and in the present study at baseline. ${ }^{14}$ Moreover, the proportion of smokers increased with increasing RF titre. ${ }^{14}$ In addition, smoking has been found to be a risk factor for RF positive rheumatoid arthritis in men. ${ }^{8}$ In view of these associations, the relative mortality risks in the present study were adjusted for smoking. At baseline, however, no comorbid disease was detected, although all the diagnoses made in the survey were analysed for their associations with false positive RF reactions. ${ }^{14}$

We conclude that both RF positive arthritis and false positive RF reactions are detrimental to longevity, but through different disease patterns. Severe chronic arthritis characterised by the presence of RF carries an increased risk of a multitude of life threatening conditions, whereas RF independent of arthritis is a risk factor for cardiovascular death. Its role may even be directly pathogenetic.

1 Cobb S, Anderson F, Bauer W. Length of life and cause of death in rheumatoid arthritis. $N$ Engl f Med 1953; 249: 553-6.

2 Symmons D P M. Mortality in rheumatoid arthritis. $\mathrm{Br} f$ Rheumatol 1988; 27 (suppl 1): 44-54.

3 Pincus T, Callahan L F. The 'side-effects' of rheumatoid arthritis: joint destruction, disability and early mortality. Br f Rheumatol 1993; 32 (suppl 1): 28-37.

4 Wolfe F, Mitchell D M, Sibley J T, et al. The mortality of rheumatoid arthritis. Arthritis Rheum 1994; 37: 481-94.

5 Linos A, Worthington J W, O'Fallon W M, Kurland L T. The epidemiology of rheumatoid arthritis in Rochester Minnesota: a study of incidence, prevalence, and mortality. Am 7 Epidemiol 1980; 111: 87-98.

6 Allebeck P, Ahlbom A, Allander E. Increased mortality among persons with rheumatoid arthritis, but where RA does not appear on death certificate. Scand $\mathcal{F}$ Rheumatol 1980; 10: 301-6.

7 Jacobsson L T H, Knowler W C, Pillemer S, et al. Rheumatoid arthritis and mortality. A longitudinal study on Pima Indians. Arthritis Rheum 1993; 36: 1045-53.

8 Heliövaara M, Aho K, Aromaa A, Knekt P, Reunanen A. Smoking and risk of rheumatoid arthritis. $\mathcal{F}$ Rheumato 1993; 20: 1830-5.

9 Aho K. Autoantibodies and the risk of death. Med Biol 1980 58: 8-13.

10 Mackay J R, Whittingham S F, Mathews J D. The immunoepidemiology of aging. In: Makidonan T, Yunis T, eds. Immunology of aging. New York: Plenum Publishing Corporation, 1977; 35-49.

11 Aho K, Salonen J T, Puska P. Autoantibodies predicting death due to cardiovascular disease. Cardiology 1982; 69: death due.

12 Aho $\mathrm{K}$, Heliövaara $\mathrm{M}$, Sievers $\mathrm{K}$, Maatela J, Isomäki $\mathrm{H}$ Clinical arthritis associated with positive radiological and serological findings in Finnish adults. Rheumatol Int 1989 9: 7-11.

13 Aho K, Heliövaara M, Maatela J, Tuomi T, Palosuo T. Rheumatoid factors antedating clinical rheumatoid arthritis. F Rheumatol 1991; 18: 1282-4

14 Tuomi T, Heliövaara M, Palosuo T, Aho K. Smoking, lung function, and rheumatoid factors. Ann Rheum Dis 1990; 49: 753-6.

15 Aromaa A, Heliövaara M, Impivaara $\mathrm{O}$, et al. Health functional limitations and need for care in Finland. Basic results from the Mini-Finland Health Survey [in Finnish with English summary]. Helsinki and Turku: Publications with English summary]. Helsinki and Turku: Pub

16 Heliövaara $M$, Aromaa A, Klaukka T, Knekt $P$, Joukamaa M, Impivaara O. Reliability and validity of interview data on chronic diseases. The Mini-Finland Health Survey. F Clin Epidemiol 1993; 46: 181-91.

17 Kellgren J H, Jeffrey M R, Ball J R. The epidemiology of chronic rheumatism, Vol II. Atlas of standard radiographs of arthritis. Oxford: Blackwell, 1963.

18 Larsen A, Dale K, Eek M. Radiographic evaluation of rheumatoid arthritis and related conditions by standard reference films. Acta Radiol 1976; 18 (suppl): 481-91.

19 Cox D R. Regression models and life-tables. $f R$ Stat Soc B 1972; 34: 187-220.

20 Isomäki $\mathrm{H}$, Kaarela $\mathrm{K}$. Contrasts between epidemiological and clinical concepts of rheumatoid arthritis. Scand $\mathfrak{f}$ and clinical concepts of rheumatoid

21 Accini L, Dixon F L. Degenerative vascular disease and myocardial infarction in mice with lupus-like syndrome. Am F Pathol 1979; 96: 477-92.

22 Minick C R. Immunological arterial injury in atherogenesis. Ann NY Acad Sci 1976; 275: 210-27.

23 Poston R N, Davies D F. Immunity and inflammation in the pathogenesis of atherosclerosis. Atherosclerosis 1974; 19: 353-67.

24 Puurunen $M$, Mänttäri $M$, Manninen V, et al. Antibody against oxidized low-density lipoprotein predicting myocardial infarction. Arch Intern Med 1994; 154: 2605-9.

25 Aho K, Kurki P. Seropositive versus seronegative rheumatoid arthritis-time for a new definition. $\mathcal{F}$ Rheumato 1994; 21: 388-90.

26 Mathews J D, Hooper B M, Whittingham S, Mackay J R, Stanhouse N S. Association of autoantibodies with
smoking, cardiovascular morbidity, and death in the Busselton population. Lancet 1973; ii: 754-8. 